\title{
Mulemba
}

Revista Angolana de Ciências Sociais

5 (10) | 2015

Angola 40 anos de independência: memória, identidades, cidadania e desenvolvimento

\section{«...E os Meninos de há 40 anos, o que aprenderam?...»}

"... And the Boys of 40 years ago, what did they learn?..."

\section{Cesaltina Abreu}

\section{(2) OpenEdition}

\section{Journals}

Edição electrónica

URL: http://journals.openedition.org/mulemba/1710

DOI: $10.4000 /$ mulemba. 1710

ISSN: 2520-0305

\section{Editora}

Edições Pedago

\section{Edição impressa}

Data de publição: 1 novembro 2015

Paginação: 21-29

ISSN: 2182-6471

Refêrencia eletrónica

Cesaltina Abreu, ««...E os Meninos de há 40 anos, o que aprenderam?...»», Mulemba [Online], 5 (10)।

2015, posto online no dia 10 outubro 2018, consultado o 26 janeiro 2021. URL: http://

journals.openedition.org/mulemba/1710 ; DOI: https://doi.org/10.4000/mulemba.1710 


\title{
«...E os Meninos de há 40 anos, o que aprenderam?...»*
}

\author{
Cesaltina Abreu**
}

\begin{abstract}
Resumo: Tendo como mote o refrão do poema «Meninos do Huambo» de Manuel Rui (1976), este artigo procura sintetizar uma retrospecção sobre o estado de satisfação relativamente às promessas da Dipanda dos que eram meninos(as) à data da independência há 40 anos. Essa análise organiza-se em torno de três eixos: o (dis)funcionamento da vida diária ou o desconseguir de melhorar a vida quotidiana numa base universal, as contradições/ambiguidades/frustrações da falência da «construção da angolanidade» e de formas de pertencimento e de participação, e os problemas resultantes das crescentes pobreza e desigualdade sociais.
\end{abstract}

Palavras-chave: Angola, independência, utopia, pobreza, desigualdade, criatividade, pertencimento, reconhecimento, memórias sociais.

Em 1976 Manuel Rui publicou o poema Os Meninos do Huambo (cf. Rui 1976 e Anexo, infra) e, em 1985, esse mesmo poema foi musicado e cantado em Portugal por de Paulo de Carvalho' ${ }^{1}$,

* Falhada a inclusão da minha proposta de intervenção no programa do V Colóquio da Faculdade de Ciências Sociais, Angola 40 anos de independência: Memórias, Identidades, Cidadania e Desenvolvimento, o presente texto é publicado aqui pela cortesia do seu Editor.

* Socióloga e Engenheira Agronóma. É Professora Auxiliar e Chefe do Departamento de Sociologia (DS) da Faculdade de Ciências Sociais (FCS) da Universidade Agostinho Neto (UAN) e Coordenadora da «Série Sociologia» dos Cadernos de Ciências Sociais; é docente convidada do Curso de Mestrado em Ordenamento e planeamento de áreas urbanas do Departamento de Arquitectura (DA) da Faculdade de Engenharia (FE) da UAN.

1 Cf. Paulo de Carvalho, O melhor de (1999). Universal Music Portugal - 546 590-2. CD Compilation Remastered, Faixa n. ${ }^{0}$ 16. Paulo de carvalho, nome artístico de Manuel Paulo de Carvalho Costa, nascido em Lisboa, Portugal, em 15 de Maio de 1947. Para escutar, acessar <https://www.youtube.com/ watch?v=9Qm_fqH4GCE $>$, 3:34 minutos; <https://www.youtube.com/ watch?v=Mij6ULLzUPo >, 3:37 minutos. Site <www.desafinacoes.pt.vu>. 
posteriormente, pelo músico angolano Ruy Mingas. ${ }^{2}$ Apesar de 10 anos após a independência, a letra do poema reavivou a onda de entusiasmo e esperança num futuro melhor para todos, em resultado da luta anticolonial e da independência em 1975. Este poema tem como refrão:

\section{«[...] os meninos à volta da fogueira vão aprender coisas de sonho e de verdade vão aprender como se ganha uma bandeira vão saber o que custou a liberdade [...]».}

Embora sem substituir-me ao autor, recupero emoções e expectativas que associei a esses versos desde a primeira vez que os li e, posteriormente, quando os escutei, e pergunto-me até que ponto as promessas nele contidas terão sido satisfeitas/atendidas/tidas em conta nestes 40 anos: $O$ que os Meninos de há 40 anos aprenderam?...

Na vasta obra de Manuel Rui, prosa e poesia, predominam a criatividade nas angolanizações da língua portuguesa e a liberdade nos neologismos, a reflexão crítica sobre a evolução de Angola desde a independência e o recurso ao humor ácido, tantas vezes, com a tradução em frases mordazes do desencanto e da esperança cansada de tanto esperar as promessas da independência tornarem-se realidade para todos os angolanos. Mas simultaneamente procura, numa articulação entre passado e futuro - na originalidade das suas personagens e no magistral uso dos diálogos e narrativas através dos quais fazemos sentido de nós e dos outros e nos posicionamos em relação ao que nos cerca - , recuperar sonhos e dar sentido às expectativas expressas nos «discursos» de então como forma de reavivar as «coisas de sonho e de verdade», dar sentido aos processos que permitiram «ganhar uma bandeira» para enfim poder transformar a realidade de grupos sociais dominados pelo colonialismo num quotidiano permeado de liberdades substantivas, onde a diversidade não seja um «problema» mas antes um «potencial» para a transformação social.

2 Ruy Mingas, Memória (2011). Maianga - CD 2011758. 2xCD - Compilation, faixa n. ${ }^{\circ} 11$ <https://www.discogs.com/Ruy-Mingas-Mem\%C3\%B3ria/release/5912114>. Ruy Mingas, nome artístico de Rui Alberto Vieira Dias Rodrigues Mingas, nascido em Luanda em 12 de Maio de 1939, cantor e guitarrista, musicou e interpretou o poema de Manuel Rui. Para ouvir, acessar <https://www. youtube.com/watch?v=D_naXf_c6As>, 4:25 minutos. 
Colocando-me no lugar dos Meninos de há 40 anos, ouso relacionar a reflexão sobre o que acontece em seu redor, no estado das coisas aos mais diversos níveis viajando pelo tempo; afinal, nenhuma projecção futura se faz sem alicerces na trajectória até então percorrida. A procura de entendimento da situação tal como ela se apresenta, conduzirá os Meninos de há 40 anos a um questionamento sobre o que foi projectado - e eles «herdaram» das gerações ancestrais -, e o que foi concretizado. Por muitas que sejam as realizações, certamente que as há, serão levados a concluir que a implementação do projecto da Dipanda não conduziu aos resultados esperados: irão confrontar-se, certamente, com a constatação que, nos domínios social, económico e político, tal projecto ficou longe de alcançar os objectivos que se propunha.

Procurando organizar a diversidade de problemas não ou mal resolvidos, os Meninos de há 40 anos poderão construir, pelo menos, três categorias de questões: numa, poderão enquadrar as questões relacionadas com o (dis)funcionamento da vida diária, ou seja, o desconseguir de melhorar a vida quotidiana numa base universal; noutra, colocarão as contradições/ambiguidades/frustrações da falência da componente «construção da angolanidade» e de formas de pertencimento e de participação, devido ao esvaziamento do conteúdo dos laços de cidadania nacional; finalmente, e não necessariamente nesta ordem, surgirão os problemas resultantes da sobrevalorização de valores materialistas, do supérfluo e do desperdício, das aparências, dos simulacros, da ostentação, de uns poucos mas poderosos grupos que indevidamente se apropriaram dos recursos que deveriam sustentar o bem-estar de todos, nós Hoje e os que virão Amanhã.

A primeira categoria abarca as questões de identidade, reconhecimento e pertencimento, que orientam a acção de grupos e movimentos sociais, dentro e fora do espaço territorial do Estado. A segunda, envolve igualmente questões de reconhecimento e de pertencimento, embora numa perspectiva mais ampla de criação de identidades e de cidadania nacional e supra-nacional. A terceira requer a busca por mecanismos de coordenação das decisões políticas numa perspectiva de conciliar os diversos tipos de interesses e de necessidades dos grupos sociais que coexistem no espaço-território-à-espera-da-nação, porque todos contam!

Contudo, quer o perfil das questões, quer o perfil das eventuais saídas da crise em que se encontrarão mergulhados, estão conformados por 
sentimentos de frustração e de impotência, mais ou menos generalizados, resultantes da tomada de consciência de que o modelo «esgotou-se» nos seus excessos e défices, não parecendo oferecer alternativas satisfatórias para a crise que ele próprio gerou. Confrontados com as suas conclusões, não restará aos Meninos de há 40 anos, senão duas alternativas: recolherem-se numa atitude contemplativa «de espera para ver no que dá» ou a procura, dentro de si e no seu entorno - mais ou menos amplo - , de outras maneiras de olhar o futuro, através da reinvenção de si próprios e do seu estar em sociedade, comunidade ou grupo ao qual se vinculam por laços de solidariedade, da sociedade que lhes aporta o estatuto de cidadão nacional e do mundo, do qual se sentem ou desejam sentir parte, por via da realização mais acabada e melhor conseguida da sua condição de Ser Humano e Cidadão.

Os caminhos utópicos que a imaginação terá de percorrer para construir essa nova realidade deparam-se, desde logo, com inúmeros problemas e constrangimentos, os quais apenas serão ultrapassados se, e na medida em que, o potencial inovador de que são portadores se liberte através de um processo de auto-reflexão individual e grupal e da capacidade de difusão dessas utopias, por via de interacções sociais aos diversos níveis, ou seja, se se permitirem ultrapassar as barreiras conceituais que pretendem conformar o seu pensamento e comportamento. E, acima de tudo, se vencerem o medo, porque afinal acontecimentos recentes nos mostraram que enquanto «Nós», Podemos!...

Como até aqui desconseguimos, procuremos pelo menos alimentar-nos de esperanças recentemente reerguidas de que «nem tudo está perdido» e contribuir para o esclarecimento das questões que os Meninos de há 40 anos colocam hoje em dia à cidadania e que terão, necessariamente, de ser «bem» resolvidas, caso o objectivo seja, realmente, a construção de algo novo, um legado ao futuro mais coerente com a condição de seres humanos que somos. Para tal, é mister ser realistas nas nossas abordagens sobre o «agora», não deixando de sonhar um «amanhã» melhor e, acima de tudo, acreditando que o sonho é possível.

Mas para isso, será necessário recorrer

- à criatividade, para construir uma nova estruturação das relações sociais aos diversos níveis da interação local, nacional e internacional, porque através da interacção criativa e reflexiva pode 
produzir-se um leque de alternativas possíveis para os prenunciados caminhos de mudança através da transformação social; a sociedade tem uma capacidade inesgotável de inovação e criatividade capaz de gerar novos conceitos e de os materializar de forma harmoniosa e adequada aos diversos contextos, desde que o Estado e os poderes instituídos desenvolvam capacidades de com ela trabalharem (o que não tem sido o nosso caso);

- a novos/nossos conceitos de pertencimento e de reconhecimento necessários para a construção da Nação aos diversos níveis; através da ideia de Angolanidade ou outra funcionalmente equivalente, indivíduos e grupos reconhecem-se como pertencentes a uma colectividade, a um grupo, a uma nação. Através das interacções e processos de selecção pelos quais se constrói a dimensão hermenêutica do sistema social, ou seja, através de mecanismos de comunicação simbólica dentro e entre as colectividades, a construção dessa dimensão poderá acontecer por consenso ou dialogicamente. Ao contrário, o exercício do poder pressupõe a imposição, incluindo o recurso à coerção. A história ensina que a abertura é necessária à reinterpretação pelos diversos actores e grupos sociais do seu passado colectivo (em especial dos conflitos), à passagem de direitos individuais a direitos colectivos e à redefinição de fronteiras entre os grupos e destes com o exterior, criando as condições para um processo de educação em moralidade de grupo;

- e às memórias sociais de indivíduos, grupos sociais, comunidades, sociedades e nações, comummente construídas e partilhadas, fundamentais para o estabelecimento de relações de confiança entre os constituintes da nação. Este processo implica a reconstrução crítica das memórias colectivas dos grupos abrindo uma nova perspectiva de construção de um consenso nacional não apenas baseado nas regras e memória colectiva do grupo dominante e/ou vencedor, mas na busca comum de uma visão mutuamente aceitável de futuro respaldada numa visão partilhada e aceite do passado. Somando os esforços e as vontades de todos, serão produzidas novas bases de cooperação numa sociedade consciente de si própria, progressivamente mais tolerante, mais confiável e confiante, capaz de legitimar a sua identidade face à pluralidade e à globalização, e de encarar o desafio que esses processos representam aos seus «limites» e «fronteiras» económicos, culturais e políticos, recorrendo aos tais novos/nossos critérios 
de legitimação de novas identidades, na medida em que as tradições também contribuem para gerar identidades criativas, construir novos usos e costumes através do resgate de formas tradicionais de ser e pensar em sociedade e das suas articulações com o tempo do mundo.

E, voltando a Manuel Rui, desta feita em Janela de Sónia (2009), porque não tentarmos, ainda que simbolicamente, um novo começo, uma «nova independência, democrática, de igualdade e sem medo", pois, "No quê que temos mais para acreditar? Independência não era festa? E então não é só morrer atoamente? O menino desculpa, mas temos de começar outra independência até acabar a guerra e a fome e as pessoas dizerem bom dia sem medo» (cf. RuI 2009: 376).

A guerra já acabou, falta-nos dar conta da fome e do medo!

\section{Referências bibliográficas}

Rui Manuel

2009, Janela de Sónia. Romance. Luanda, União dos Escritores Angolanos.

1976, «Meninos do Huambo», in 11 Poemas em Novembro: Ano 1. Luanda, União dos Escritores Angolanos [«Cadernos Lavra \& Oficina»; 1], 56p.

\section{Discografia}

\section{Carvalho Paulo de}

2004, "Os Meninos do Huambo", in A arte e a música de Paulo de Carvalho (Álbum), data de lançamento: 2004. Disponível em <https://www.youtube.com/watch?v=Mij6ULLzUPo> 2010, "Os Meninos do Huambo», in Música Popular Tuga, 7/4/2010, disponível em

$<$ https://www.youtube.com/watch?v.=9Qm_fqH4GCE $>$ e $<$ www.letras.mus.br $>$

Mingas Rui

«Os Meninos do Huambo», disponível em

$<$ https://www.youtube.com/watch?v=D_naXf_c6AS >

$<$ https://www.youtube.com/watch?v=JpeYSKfHvF4>

$<$ www.angomais.com $>$

$<$ www.letras.mus.br $>$

< bda.ao/yetu/olhares/o-exito-de-os-meninos-do-huambo> 
Recepção do manuscrito: 16/01/2016

Aceite para publicação: 30/01/2016

Title: «... And the Boys of 40 years ago, what did they learn?...»

\begin{abstract}
With the refrain of the poem «Meninos do Huambo» by Manuel Rui (1976), this article seeks to synthesize a retrospective about how those who were boys at the time of independence 40 years ago years look nowadays to the Dipanda promises. This analysis is organized around three axes: the (dis) functioning of daily life or the misconception of improving daily life on a universal basis, the contradictions / ambiguities / frustrations of the bankruptcy of the "construction of Angolanity" and forms of belonging And participation, and the problems resulting from growing social inequality and poverty.
\end{abstract}

Keywords: Angola, independence, utopia, poverty, inequality, creativity, belonging, recognition, social memories.

\title{
Anexo
}

\section{Os Meninos do Huambo*}

Com fios feitos de lágrimas passadas

Os meninos do Huambo fazem alegria

Constroem sonhos com os mais velhos de mãos dadas

E no céu descobrem estrelas de magia

Com os lábios de dizer nova poesia

Soletram as estrelas como letras

E vão juntando no céu como pedrinhas

Estrelas letras para fazer novas palavras

Os meninos à volta da fogueira

Vão aprender coisas de sonho e de verdade

Vão aprender como se ganha uma bandeira

Vão saber o que custou a liberdade

Com os sorrisos mais lindos do planalto

Fazem continhas engraçadas de somar

Somam beijos com lores e som suor

E subtraem manhã cedo por luar 
Dividem a chuva miudinha pelo milho

Multiplicam o vento pelo mar

Soltam ao céu as estrelas já escritas

Constelações que brilham sempre sem parar

Os meninos à volta da fogueira

Vão aprender coisas de sonho e de verdade

Vão aprender como se ganha uma bandeira

Vão saber o que custou a liberdade

Palavras sempre novas, sempre novas

Palavras deste tempo sempre novo

Porque os meninos inventaram coisas novas

$E$ até já dizem que as estrelas são do povo

Assim contentes à voltinha da fogueira

Juntam palavras deste tempo sempre novo

Porque os meninos inventaram coisas novas

E até já dizem que as estrelas são do Povo

* In Manuel Rui, 11 Poemas em Novembro: Ano 1. Luanda, União dos Escritores Angolanos [«Cadernos Lavra\&Oficina»; n. ${ }^{0} 1$ 1], 1976.

\section{Cesaltina Abreu}

Cesaltina Abreu é actualmente Professora Auxiliar, Chefe do Departamento de Sociologia da Faculdade de Ciências Sociais (FCS) da Universidade Agostinho Neto (UAN) e docente convidada do Curso de Mestrado em Ordenamento e planeamento de áreas urbanas do Departamento de Arquitectura (DA) da Faculdade de Engenharia (FE) da UAN; é Coordenadora da «Série Sociologia» dos Cadernos de Ciências Sociais.

É licenciada em Agronomia (1977) pela Universidade de Luanda (curso superior de Agronomia, Huambo), mestre (2001) e doutorada (2006) em Sociologia pelo Instituto Universitário de Pesquisas do Rio de Janeiro (IUPERJ), actualmente IESP/UERJ, República Federativa do Brasil. A sua dissertação de mestrado intitula-se Participação faz diferença? Reflexões na avaliação do Fundo de Apoio Social (FAS) no sudoeste de Angola (Huíla, Namibe e Kunene); e a tese de doutoramento tratou da Sociedade civil em Angola. Da realidade à utopia, mantendo-se inéditos ambos os trabalhos. Obteve em 2013 o Certificado em estudos avançados em prática académica (CASAP), módulos 1 e 2, na Universidade de Newcastle, Reino Unido da Grã Bretanha.

As suas áreas de interesse no âmbito da Sociologia Política envolvem questões multidimensionais da cidadania, análise de contexto, 
abordagens de «desenvolvimento», sustentabilidade e ambiente, capital humano e social, participação, direitos humanos e justiça social, cultura cívica, espaço público e sociedade civil, memória social, confiança e tolerância.

Publicou, entre outros, os materiais seguintes: a) livro: $A$ actualidade do pensamento de Alexis de Tocqueville na tensão entre igualdade e liberdade e entre indivíduo e sociedade nos processos de democratização contemporâneaos (Luanda, Edições Mulemba; Ramada, Edições Pedago, 2016, 108p. [«Cadernos de Ciências Sociais: Série Sociologia»; 3]); b) em capítulo de livros: «Cidadania e participação em Angola. Que papel para a sociedade civil?», in Boaventura de Sousa Santos e José Octávio Serra Van-Dúnem (orgs.), Sociedade e Estado em construção: Desafios do Direito e da Democracia em Angola - Luanda e justiça: Pluralismo jurídico numa sociedade em transformação, volume I, Coimbra, Almedina, 2011, pp. 369-403; "Angola, SADC e a globalização», in Jonuel Gonçalves (org.), Atlântico Sul XXI. América do Sul e África na virada do milénio. São Paulo, Editora Unesp, pp. 185-207; "A sociedade civil em Angola e seus desafios internos e externos», in Nuno Vidal e Justino Pinto de Andrade, Sociedade civil e política em Angola. Enquadramento regional e internacional, Luanda e Lisboa, Edições Firmamento e Média xxi, 2008, pp. 101-114; b) artigos: «Pobreza em Angola: Percepções, acção colectiva e os dilemas de participação com base numa pesquisa qualitativa», Mulemba - Revista Angolana de Ciências Sociais (Luanda), vol. v, n. ${ }^{\circ}$ 9, Maio de 2015, pp. 319-344; «Para uma perspectiva sobre a prática das Ciências Sociais: Uma leitura de Charles C. Ragin, Constructing social research: the unity and diversity of method», Mulemba - Revista Angolana de Ciências Sociais (Luanda), vol. v, n. ${ }^{\circ}$ 9, Maio de 2015, pp. 525-555; «Globalização: Da transformação do espaço social à oportunidade de mudança social», Mulemba - Revista Angolana de Ciências Sociais (Luanda), vol. Iv, n. ${ }^{o}$ 8, Novembro de 2014, pp. 393-422; «Revisitando uma obra exemplar: Dialectic of enlightenment. Philosophical fragments de Teodor Adorno \& Max Horkheimer», Mulemba - Revista Angolana de Ciências Sociais (Luanda), vol. Iv, n. ${ }^{\circ}$ 8, Novembro de 2014, pp. 641-658; «Concepções e práticas pedagógicas no ensino das ciências sociais e humanas", Mulemba - Revista Angolana de Ciências Sociais (Luanda), vol. IV, n. ${ }^{\circ}$ 7, Maio de 2014, pp. 291-306 (em parceria com Eugénio da Silva e Pedro Manuel Patacho); «Em busca da (re)organização da vida em Angola», Mulemba - Revista Angolana de Ciências Sociais, vol. II, n. ${ }^{\circ}$ 3, Maio de 2012, pp. 103-127; «Desigualdade social e pobreza: ontem, hoje e (que) amanhã?, RAS - Revista Angolana de Sociologia (Luanda), n. ${ }^{\circ}$, Junho de 2012, pp. 93-111.

[e-mail: tinaabreu@yahoo.com.br]

[e-mail: tinaabreu@hotmail.com] 